\title{
Should Research Thesis be a Prerequisite for Doctor of Medicine Degree? A Cross-sectional Study at Jordan University of Science and Technology
}

Aisha Gharaibeh,' Yazan S. Mousa. ${ }^{7}$

\begin{abstract}
Background: University based research is an integral part of many prestigious medical schools worldwide. The benefits of student-conducted research have long been highlighted in the literature. This article aims to identify the insights of medical students concerning research training, including perceived hurdles in the way of conducting research, and the utility of a research thesis in acquiring a Doctor of Medicine degree. Methods: A total of 808 medical students at Jordan University of Science and Technology were selected by random sampling with a confidence level of $95 \%$. A survey was constructed by a group of students through literature review and group discussions. The survey utilized polar and Likert scale questions to collect data from the students. Statistical inferences were then obtained through analysis of means and one sample t-test of the hypothesis. Results: A total of 687 students filled out the survey ( $85 \%$ ). Analysis shows that respondents have a strong and positive attitude towards research. The respondents with past research experience constituted $14.3 \%$ of those surveyed. Those respondents identified the barriers faced by them during their experience. The students showed high degree of agreement that a research thesis should be a prerequisite for graduation with statistical significance of $p$-value, 0.05 . Conclusion: Modifying the curriculum to include research methodology is recommended, and developing it to incorporate a thesis as a requirement for graduation may be advised upon further review.
\end{abstract}

Keywords: Medical Students, Jordan, Biomedical Research, Educational Needs Assessment (Source: MeSH-NLM).

\section{Introduction}

About the author: Aisha is a fifth-year medical student at JUST. She is a recipient of Jordan Ministry of Higher Education and Scientific Research scholarship for Distinguished Students to study Medicine and Surgery between the years 2009 and 2015.
Submission: Nov, 15, 2013 Acceptance: Jan. 5, 2014 Process: Peer-reviewed
It is now well-established that research is a corner stone of medical education; it has always been the platform upon which a well oriented physician stood to be an integral part of academic and applied medicine.

Previous literature has proposed that involving medical students in research early in their careers is a long-term strategy for promoting health research. ${ }^{2,3}$ In Germany, for example, medical students contributed to $28 \%$ of the publications in one institution, including first authorship in $7.8 \%$ of papers. ${ }^{4}$ In Croatia, $23 \%$ of undergraduate students have been involved in scientific research, with $38 \%$ publishing their results. 5

Furthermore, if the experience of doing research as a student does not lead to a later career in academic medicine, a research experience can help in improving students' skills in searching and critically appraising the published medical literature, as well as obtaining skills to pursue independent research and publication. ${ }^{6,7}$

In Jordan however, the percentage of undergraduate research and medical student's perception of it remain unclear. Another issue that is debated in the field of medical education is the integration of research as part of medical school's curriculum or as a mandatory requirement for graduation from medical school. ${ }^{8}$

Jordan has been ranked as the country with the highest number of researchers per million people out of the 57 members of the Organization of Islamic Countries (OIC), with 1,927 researchers per million people in Jordan as opposed to an average of 500 for the OIC. ${ }^{9}$ This number puts Jordan ahead of countries like Greece, Israel and Italy, and close to that of the United Kingdom and Ireland. That being said, Jordanian medical schools are lacking in terms of postgraduate research programs, such as a Master's or PhD degree, translating to weak medical research in the educational infrastructure. Furthermore, a public study showed a high tendency toward investing in research as a country, ${ }^{10}$ making biomedical research in Jordan not only an educational need, but a national issue as well.

The aim of this study is to assess the opinion of medical students at Jordan University of Science and Technology as to whether a research thesis should be a prerequisite for Medical Doctorate degree, and identify the barriers students face when conducting research. The conclusions of this study are expected to aid decision makers in medical education to make an

${ }^{1}$ Jordan University of Science and Technology, ArRamtha, Irbid, Jordan. 
evidence-based decision in improving the curriculum, supporting the already established literature on the significance of involving medical students in research activities.

\section{Methods}

This cross-sectional study utilized a structured, self-administered questionnaire, constructed using Google forms. It is best described as a cross-sectional observational study design in that it was used to collect data from medical students at a specific point in time. The rationale for using a questionnaire to collect data was that it was the most efficient way to gather the data directly from students. The variables tested were independent, categorical variables, some of them were nominal, others were dichotomous, or ordinal, depending on the nature of the question.

The authors followed the recommendations of the Strengthening the Reporting of Observational Studies in Epidemiology (STROBE) Statement in writing this article." The STROBE Statement checklist of items that should be included in reports of cross-sectional studies was adhered to as a guideline.

Participants were chosen by simple random sampling. The sampling frame were the registration lists, which include all student demographic data and contact information. The questionnaire was distributed in electronic format via e-mail to 808 medical students at Jordan University of Science and Technology (JUST), first- through sixth-year, confidence level $95 \%$ with confidence interval of 3 . The total target population count was 3329 students; the number of students enrolled in the JUST Faculty of Medicine, from first- through sixth-year, in the academic year 2012/2013. It was distributed between April $15^{\text {th }}-30^{\text {th }}$,
2013. Questionnaires were filled out by 687 students (85.0\%).

The questionnaire used in this study was designed by a group of students using thorough literature review and through group discussion, under the guidance of the authors and a professor in medical education. It was validated by experts in biostatics and questionnaire construction. The survey was pilot-tested by 25 students for face-validity and comprehensibility before study commencement. ${ }^{12,13}$ Those 25 students were randomly selected to answer the questionnaire draft on paper. The idea of the study was explained to those students, and feedback was collected for format, clarity and filling time.

The questionnaire intended to poll the opinion of medical students at JUST about research as a prerequisite for graduation from medical school. It consisted of three pages with 20 questions, English language was used considering that it is the medium of instruction at the faculty. Eight questions assessed the demographic aspects of the participants. Six questions assessed the students' attitudes towards research. Six questions assessed the perception of barriers for conduction of research and whether it should be a prerequisite for graduation. These last six questions were only for those who had previous experience in research (a question asked before this part). Those 5 questions utilized the 5 -point Likert Scale, ${ }^{14}$ and were close-ended with possible responses including: strongly agree, agree, neutral, disagree, and strongly disagree; with 5 as strongly agree and 1 as strongly disagree. The same applied to questions on their perception about research. According to our pilot study, the students needed an average of 5 minutes to complete the questionnaire.

Table 1. Characteristics of Students who responded to the Electronic Questionnaire at Jordan University of Science and Technology

\begin{tabular}{|c|c|c|}
\hline Variable & Frequency (total 687) & Percent (\%) \\
\hline Mean age (years) & 21.12 & - \\
\hline Male gender & 380 & 55.31 \\
\hline \multicolumn{3}{|l|}{ Level of study (year) } \\
\hline $1^{\text {st }}$ & 92 & 13.39 \\
\hline $2^{\text {nd }}$ & 155 & 22.56 \\
\hline $3^{\text {rd }}$ & 160 & 23.29 \\
\hline $4^{\text {th }}$ & 157 & 22.85 \\
\hline $5^{\text {th }}$ & 80 & 11.64 \\
\hline $6^{\text {th }}$ & 43 & 6.26 \\
\hline Jordan as country of origin & 369 & 53.71 \\
\hline Public secondary school & 413 & 60.1 \\
\hline \multicolumn{3}{|l|}{ University grade point average } \\
\hline Pass (less than 70) & 80 & 11.64 \\
\hline Good or very good (70 - lower than 80 ) & 223 & 32.46 \\
\hline Excellent or distinguished (higher than 80 ) & 384 & 55.90 \\
\hline \multicolumn{3}{|l|}{ Father's educational level } \\
\hline Master/PhD & 267 & 38.86 \\
\hline Diploma/Bachelor & 316 & 46.00 \\
\hline Primary or secondary school & 104 & 15.14 \\
\hline \multicolumn{3}{|l|}{ Mother's educational level } \\
\hline Master/PhD & 97 & 14.12 \\
\hline Diploma/Bachelor & 438 & 63.76 \\
\hline Primary or secondary school & 152 & 22.12 \\
\hline Involved in extra-curricular activities & 304 & 44.25 \\
\hline
\end{tabular}


The Statistical Package for Social Sciences (SPSS) version 20.0 was used for all data entry and analyses. ${ }^{15}$ All descriptive statistics were presented as proportions. Statistical inferences were obtained through analysis of means and one sample t-test to test the hypothesis. P-values $\leq 0.05$ were regarded as statistically significant.

\section{Results}

Six-hundred-eighty-seven (687) students responded to the questionnaire out of a total of 808 students received it. The mean age of respondents was 21.1 (SD 1.88). Males constituted $55.31 \%$ while females only $44.69 \%$ of respondents, in contrast to the actual percentage of males at the JUST Faculty of Medicine $(48 \%)$, rendering males overrepresented in the study. The proportions of respondents from second, third and fifth-year levels of study were similar to their corresponding proportions at JUST, while first and sixth year students were underrepresented ( 13.38 and $6.26 \%$ compared to an actual 18.49 and $9.01 \%$, respectively), and fourth year students were overrepresented (22.85\% compared to an actual $15.0 \%$ ).

Non-Jordanians constituted $44.69 \%$ of respondents from at least twenty different countries. Slightly less than two-thirds reported graduating from a public secondary school. More than half of respondents have a Grade Point Average (GPA) higher than $80 \%$. The highest proportion of medical students described their parents' educational level as completion of a diploma or bachelor's degree. Nearly $44 \%$ of respondents were involved in extra-curricular activities. These characteristics are summarized in Table 1. All the questions were accounted for and there was no missing data. The Google forms' "make this item required" option was utilized in the majority of questionnaire items, but even questions that weren't set as mandatory were completed fully by respondents.

Analyses show that respondents have a strong and positive attitude towards research, as assessed using a 5-point Likert scale. The mean indicated high agreement degree (around 4.5) for biomedical research as an opportunity to improve one's scientific knowledge and to develop critical and analytical thinking. With a slightly less degree, students highly agreed to associate physician success with respective research experience. With a mean of 3.4, students were in less agreement that research is time consuming on the expense of curricular studying. See Table 2.
The number of respondents with past research experience was 98 students (14.3\%). These students were asked further questions to identify barriers they faced when conducting research. There was a high degree of agreement with the barriers pre-specified by the questionnaire constructors with a mean of 3.95. These barriers are summarized in Table 3.

The hypothesis tested was whether there is a statistically significant effect of medical students' opinion that a research thesis should be a prerequisite for graduation from medical school, at a significance level of alpha, 0.05 . To test this hypothesis, one sample t-test was applied to explore effect for the medical students' attitudes toward research and whether it should be a prerequisite for graduation (test value 3 for five Likert scale). The mean was 3.89 with standard deviation of 0.75 and degree of freedom of 686 . The one sample t-test statistic was 31.230 $(p=0.00)$ indicating that the mean of 3.89 is statistically significant and we can accept the hypothesis.

\section{Discussion}

The results of this study confirm that, at the time of administration of the questionnaire, medical students at JUST had a positive attitude about joining research activities to increase their scientific knowledge, as well as enhancing their skills of critical and analytical thinking. Students also expressed positive perceptions for development of a curriculum that includes a research thesis as a prerequisite for graduation. This indicates that students at the Faculty of Medicine at JUST are interested in research from a theoretical point of view, and comes in direct correlation with the institutional ranking as the top research university in the country. ${ }^{16}$

On the other hand, results clearly show that the number of research participants does not meet the aspirations of the students, or the vision of the university at large to become a regional pioneer in research through promotion of research among its students. Taken together, respondents are positive about joining research activities, and it is the responsibility of decision making personnel at the faculty to take proper measures in integrating research and possibly a thesis into the medical curriculum. The prospect of establishing a medical PhD program may also be worth consideration.

Limitations of our study include the notion that perhaps only students interested in research to begin with took part in the study, which may explain the $15 \%$ who chose not to respond as

Table 2. Responding Student Perceptions of Research at JUST

\begin{tabular}{|c|c|c|c|c|c|}
\hline No. & Items & Mean & Standard Deviation & Rank & Agreement Degree \\
\hline 1 & $\begin{array}{l}\text { Biomedical research gives the medical student an opportunity to } \\
\text { improve his/her scientific knowledge }\end{array}$ & 4.53 & 0.65 & 1 & High \\
\hline 2 & $\begin{array}{l}\text { Biomedical research helps in development of critical and analyti- } \\
\text { cal thinking }\end{array}$ & 4.53 & 0.63 & 1 & High \\
\hline 3 & $\begin{array}{l}\text { Involvement in biomedical research as a student consumes time } \\
\text { at the expense of curricular studying. }\end{array}$ & 3.41 & 0.92 & 5 & Medium \\
\hline 4 & A successful physician is an experienced researcher & 3.98 & 0.90 & 3 & High \\
\hline 5 & $\begin{array}{l}\text { Research should be set in medical school curriculum as a requi- } \\
\text { site for graduation. }\end{array}$ & 3.81 & 1.00 & 4 & High \\
\hline Tota & & 4.05 & 0.83 & - & High \\
\hline
\end{tabular}


Original Article

Table 3. Perceived Barriers by Medical Students to Conduct Research

\begin{tabular}{|c|c|c|c|c|c|}
\hline No. & Items & Mean & Standard Deviation & Rank & Agreement Degree \\
\hline 1 & Access to facilities such as laboratories and samples. & 3.87 & 0.88 & 4 & High \\
\hline 2 & Funding (finding financial support). & 3.91 & 0.95 & 3 & High \\
\hline 3 & Lack of research supervision and guidance. & 4.01 & 0.94 & 1 & High \\
\hline 4 & Lack of good support from the laboratory staff. & 4.00 & 0.93 & 2 & High \\
\hline \multicolumn{2}{|c|}{ Total Means } & 3.95 & 0.64 & - & High \\
\hline
\end{tabular}

being uninterested, and might lead us to interpret the results obtained as being an overrepresentation of the actual number of students who deemed research a topic of interest.

In addition to results obtained about perceived barriers to conduct research by medical students, who strongly identified with the constraints set forth in the questionnaire, further investigation may be necessary to highlight barriers as perceived by faculty and staff members themselves. Another issue that should be emphasized is a large student-teacher ratio which may render research activities impractical. Faculty may be unwilling to include students in research that may impede career prospects, or consume time at the expense of clinic hours. ${ }^{17}$

The present study was conducted in light of many purposes, among which is the increasing awareness of engagement of medical students in research projects to improve their academic and clinical reasoning It has been highlighted in previous literature that in many developing countries including Jordan, research is not a mandatory component of medical education, ${ }^{18}$ and is largely under-represented even though such experiences can have a positive impact on the quality of medical education. ${ }^{2,3,19}$

Medical students in Germany, for instance, are obliged to write a research thesis to acquire the title of medical doctor. ${ }^{4}$ In a study by ogunyemi $D$ et al. in California, students were able to conduct and present a primary care research project as a requirement of their medical training, and most students found the experience to be beneficial and positive. ${ }^{20}$ However, a study by Frishman WH. in New York found that although $97 \%$ of students felt that the research experience was a useful replacement for fourth-year electives, only $18 \%$ responded that it should be a requirement for graduation. ${ }^{13}$

This study has brought us to conclude that research initiatives by medical students at JUST may be insufficient, and that this likely negatively affects the quality of education at the faculty, as well as the overall scientific output from this institute of higher learning. Modifying the curriculum to include research methodology as a first phase is recommended, and developing it to incorporate a thesis as a requirement for graduation may be advised upon further review. The ten suggestions in Boyor's report for improving undergraduate education to make research-based learning the standard may serve as guidelines for future improvement in the university's curriculums. ${ }^{21}$ 


\section{References}

1. Institute of Medicine. Beyond the HIPAA Privacy Rule: Enhancing Privacy, Improving Health Through Research. Washington, DC: The National Academies Press. 2009;111-22.

2. Aslam F, Shakir M, Qayyum MA. Why medical students are crucial to the future of research in South Asia. PLoS Med. 2005;2(11):e322.

3. Khan H, Khawaja MR, Waheed A, Rauf MA, Fatmi Z. Knowledge and attitudes about health research amongst a group of Pakistani medical students. BMC Med Educ. 2006;6:54.

4. Cursiefen C, Altunbas A. Contribution of medical student research to the Medline-indexed publications of a German medical faculty. Med Educ. 1998;32(4):439-40.

5. Kolcic I, Polasek 0, Mihalj H, Combac E, Kraljevic V, Kraljevic I, et al. Research involvement, specialty choice, and emigration preferences of final year medical students in croatia. Croat Med J. 2005;46(1):88-95.

6. Houlden RL, Raja JB, Collier CP, Clark AF, Waugh JM. Medical students' perceptions of an undergraduate research elective. Med Teach. 2004;26(7):65961.

7. Siemens DR, Punnen S, Wong J, Kanji N. A survey on the attitudes towards research in medical school. BMC Med Educ. 2010;10:4.

8. Mostafa SR, Khashab SK, Fouaad AS, Abdel Baky MA, Waly AM. Engaging undergraduate medical students in health research: students' perceptions and attitudes, and evaluation of a training workshop on research methodology. J Egypt Public Health Assoc. 2006;81(1-2):99-118.

9. Butler D. Islam and Science: the data gap. Nature. 2006;444(7115):26-7.

10. Ahram M, Othman A, Shahrouri M. Public support and consent preference for biomedical research and biobanking in Jordan. Eur J Hum Genet. 2013; 21(5): 567-70.

11. von Elm E, Altman DG, Egger M, Pocock SJ, Gotzsche PC, Vandenbroucke $J \mathrm{P}$, et al. The Strengthening the Reporting of Observational Studies in Epide- miology (STROBE) statement: guidelines for reporting observational studies. Lancet. 2007;370(9596):1453-7.

12. Van Teijlingen ER, Rennie AM, Hundley V, Graham W. The importance of conducting and reporting pilot studies: the example of the Scottish Births Survey. J Adv Nurs. 2001;34(3):289-95.

13. Frishman WH. Student research projects and theses: should they be a requirement for medical school graduation? Heart Dis. 2001;3(3):140-4.

14. Drinkwater BL. A comparison of the direction-of-perception technique with the Likert method in the measurement of attitudes. J Soc Psychol. 1965;67(2):189-96.

15. IBM Corp. Released 2011. IBM SPSS Statistics for Windows, Version 20.0. Armonk, NY: IBM Corp.

16. Statistical, Economic, and Social Research and Training Centre for Islamic Countries. Academic Rankings of universities in the OIC Countries: A Preliminary Report. 2007 April.

17. Forester JP, McWhorter DL. Medical students' perceptions of medical education research and their roles as participants. Acad Med. 2005;80(8):780-5.

18. Pawar DB, Gawde SR, Marathe PA. Awareness about medical research among resident doctors in a tertiary care hospital: A cross-sectional survey. Perspect Clin Res. 2012; 3(2):57-61.

19. Sumathipala A, Siribaddana S, Patel V. Under-representation of developing countries in the research literature: ethical issues arising from a survey of five leading medical journals. BMC Med Ethics. 2004; 5: E5.

20. Ogunyemi D, Bazargan M, Norris K, Jones-Quaidoo S, Wolf K, Edelstein R, et al. The development of a mandatory medical thesis in an urban medical school. Teach Learn Med. 2005;17(4):363-9.

21. Alberts J, Booth WC, Glaser M, Glassic CE, Ikenberry SO, Kenny SS, O'Neil RM, Reid-Wallace C, Tien C, ct Yang CN. (1998). Reinventing Undergraduate Education: A Blueprint for America's Research Universities. Retrieved from ERIC database. (ED424840)

\section{Acknowledgments}

JUST Faculty of Medicine, especially the Dean, Dr Tawfik Daradkeh, and his assistants for their unconditional support of the scientific improvement of the Faculty students. The group members who contributed to the literature review and collecting data: Ahmad Jarrar, Haytham Abdel-qader, Hiba Salhah, Marwa Nairat, Muhamad Hariz Hazwan Mohd Zarir, Omar Shunnar, Rim Kasim Ali, Sewar Abo Arqob, Tareq Kiwan, and Zainab Yusuf.

Conflict of Interest Statement at Funding

The authors have no funding, financial relationships or conflicts of interest to disclose.

Cite as:

Gharaibeh A, Mousa YS. Should Research Thesis be a Prerequisite for Doctor of Medicine Degree? A Cross-sectional Study at lordan University of Science and Technology. Int J Med Students. 2014;2(1):8-12. 